Research Article

\title{
The Efficiency of Economic Performance, Electricity Consumption, and Environmental Pollutants in Taiwan
}

\author{
Wen-jie Zou, ${ }^{1}$ Tai-Yu Lin $\left(\mathbb{D},{ }^{2}\right.$ Yung-ho Chiu ${ }^{(1)}{ }^{3}$ Ting Teng, ${ }^{4}$ and Kuei Ying Huang ${ }^{3}$ \\ ${ }^{1}$ Institute of Economics of Fujian Normal University, Fuzhou, China \\ ${ }^{2}$ Department of Business Administration, National Cheng Kung University, No.1, University Road, Tainan City 701, Taiwan \\ ${ }^{3}$ Department of Economics, Soochow University 56, Kueiyang St., Sec. 1, Taipei 10048, Taiwan \\ ${ }^{4}$ Business School, Soochow University 56, Kueiyang St., Sec. 1, Taipei 10048, Taiwan \\ Correspondence should be addressed to Tai-Yu Lin; eickyla@gmail.com
}

Received 10 January 2020; Revised 5 April 2020; Accepted 17 April 2020; Published 5 May 2020

Academic Editor: Gaetano Zizzo

Copyright ( $\odot 2020$ Wen-jie Zou et al. This is an open access article distributed under the Creative Commons Attribution License, which permits unrestricted use, distribution, and reproduction in any medium, provided the original work is properly cited.

\begin{abstract}
Finding the balance between economic development and environmental protection is a major problem for many countries around the world. Air pollution caused by economic growth has caused serious damage to humans' living environment, and as improving energy and resource efficiencies is the first priority, many countries are targeting to move towards a sustainable environment and economic development. This study uses the modified dynamic SBM (slack-based measure) model to explore the economic efficiency and air pollutants emission efficiency in Taiwan's counties and cities from 2012 to 2015 by taking labor, motor vehicles, and electricity consumption as inputs and average disposable income as output. Particulate matter $\left(\mathrm{PM}_{2.5}\right)$, nitrogen oxide emissions $\left(\mathrm{NO}_{2}\right)$, and sulfur oxide emissions $\left(\mathrm{SO}_{2}\right)$ are undesirable outputs, whereas factory fixed assets are a carry-over variable, and the results show the following: (1) the regions with the best overall efficiency between 2012 and 2015 include Taipei City, Keelung City, Hsinchu City, Chiayi City, and Taitung County; (2) in counties and cities with poor overall efficiency performance, the average disposable income per household has no significant relationship with air pollutant emissions; (3) in counties and cities where overall efficiency is poor, the average efficiency of each household's disposable income is small; and (4) except for the five counties and cities with the best overall performance, the three air pollutants in the other fourteen counties and cities are high. Overall, the air pollution of most areas needs improvement.
\end{abstract}

\section{Introduction}

Taiwan, one of the Asian four dragons, has high energy (electricity) consumption, population, and vehicle density and severe air pollution. This study is going to explore the economic performance efficiency, energy consumption (electricity), and air pollutant emission efficiency of Taiwan.

From the World Health Organization's [1] national ranking of $\mathrm{PM}_{2.5}$ concentrations in September 2011, Taiwan ranks 32 nd among 38 survey countries. Among nearly 600 cities worldwide, Chiayi and Kaohsiung made it among the top ten. From the average concentration of $\mathrm{PM}_{2.5}$ in 2013, the risk of lung cancer and asthma in children increased to $15 \%$, with the risk from stroke, heart disease, and chronic respiratory disease increasing by $25 \%$. In 2014, more than 6,000 deaths in Taiwan were caused by exposure to $\mathrm{PM}_{2.5}$.

Indeed, $\mathrm{PM}_{2.5}$ causes damage in Taiwan. The impact of $\mathrm{CO}_{2}, \mathrm{SO}_{2}$, and $\mathrm{PM}_{2.5}$ cannot be overlooked. Most studies in the literature explore the effects of energy and environmental efficiencies on $\mathrm{CO}_{2}, \mathrm{SO}_{2}$, and $\mathrm{NO}_{2}$ emissions. Many researches analyze the energy efficiency of China. Wu et al. [2] use two-stage network DEA (data envelopment analysis) to assess China's energy conservation and emission reduction efficiency during 2006-2010. Energy saving and emission reduction in the eastern region are better than in the central and western regions. Lin and Du [3] employ the 
new nonradial directional distance function to assess regional energy and carbon dioxide emissions efficiency in China from 1997 to 2009. The results show that most of China's performances in energy use and carbon dioxide emissions are poor. Industrial sector expansion is negatively correlated with China's regional energy and $\mathrm{CO}_{2}$ emissions performance. Wang et al. [4] utilize multidirectional efficiency analysis (MEA) to look at regional energy and emissions efficiencies in China from 1997 to 2010. The eastern region is more efficient than the central and western regions. Hebei, Shanxi, Inner Mongolia, Shandong, Henan, and Hubei have higher potentials for energy conservation and emission reduction. Li et al. [5] collect energy data from 2000 to 2009 in China and analyze the impact of three internal factors (economic structure, energy consumption structure, and technological progress) on energy intensity in China using the DEA-based Malmquist method. They convert technology into three components to see the different impacts in various regions. Other researches such as [6-19] also focus on the energy efficiency of China.

Some in the literature analyze the impacts of energy and environmental efficiencies on $\mathrm{PM}_{2.5}$ emissions, such as [20-30]. Martínez [20] uses two-stage DEA to assess the energy efficiency of non-energy-intensive industries (NEISs) in Germany and Colombia from 1998 to 2005. The highest energy efficiency in non-energy-intensive industries (NEISs) in Colombia is derived from the cost minimization model, showing that energy prices are not the key to improving energy efficiency. Sueyoshi and Yuan [21] utilize the DEA model to explore regional environmental efficiency performance in China from 2013 to 2014. The Chinese government should allocate economic resources to cities located in the northwestern region (including Lanzhou, Xining, Yinchuan, and Urumqi) and strengthen stricter regulation of energy consumption in major urban environments (such as Beijing, Tianjin, Shanghai, and Chongqing). Ma et al. [22] use the spatial autoregressive model to analyze the spatial diffusion effects of $\mathrm{PM}_{2.5}$ in 152 cities in China. $\mathrm{PM}_{2.5}$ is significantly affected by geospatial and regional economies. Li et al. [23] utilize the multilevel frontiers DEA model to explore the environmental efficiency of 49 cities in China. Their results present that $\mathrm{PM}_{2.5}$ and $\mathrm{SO}_{2}$ emissions are significantly related to urban population and energy technologies.

There are two contributions of this study. First, we use small economy as the research sample. As can be seen from the above literature, most of the research on air pollutants is based on large economies, such as China. These large economies have rich natural resources and focus on industrial and manufacturing development. However, the problem of air pollution is not limited to large economies, and it cannot be overlooked in some non-industrial-oriented small economies. For example, according to the Taiwan Environmental Protection Agency's 2016 and 2017 Air Quality Monitoring Report [31], the annual air quality indicators (AQIs) hit 39.34\% and $42.1 \%$, respectively, or out of reach from a good grade of $50 \%$. The other contribution is model modification.
Most past models are still dominated by radial (Charnes, Cooper, and Rhodes model, abbreviation as CCR model; Banker, Charnes, and Cooper model, abbreviation as BCC model), nonradial (slack-based measure, abbreviation as SBM), two-stage DEA analysis, and directional distance function. However, these models employ static analysis, lack dynamic considerations, and cannot understand the changes in efficiency of energy and environmental pollutants. Thus, this study employs the modified dynamic SBM to evaluate the situation for each county and city. We utilize 19 counties and cities in Taiwan from 2012 to 2015 with data on the number of employed people, motor vehicles, and electricity consumption and take the average disposable income per household as output, $\mathrm{PM}_{2.5}$, nitrogen oxide emissions $\left(\mathrm{NO}_{2}\right)$, and sulfur oxide emissions $\left(\mathrm{SO}_{2}\right)$ as undesirable outputs (recently, the problem of air pollution has drawn the attention of many scholars; because the issue of $\mathrm{CO}_{2}$ emission has been analyzed by many researches, this study focuses on the other air pollutants $\left(\mathrm{SO}_{2}, \mathrm{NO}_{2}\right.$, and $\mathrm{PM}_{2.5}$ in Taiwan), and fixed assets as the carry-over variable). By above input and output variables, this study evaluates the economic performance, electricity consumption efficiency, and air pollutant emission efficiency of Taiwan.

\section{Research Methods}

2.1. DEA. Farrell [32] proposes the efficiency frontier, but the model is only for a single input and a single output. Charnes et al. [33] extend Farrell's theory for multiple inputs and multiple outputs, naming it the CCR model. Banker et al. [34] propose their BCC model, which can determine variable returns to scale. For the first time, Tone [35] proposes nonradial and nonoriented estimation methods through slacks, calling it the SBM model. Many efficiency assessment methods have been subsequently proposed, such as super DEA, hybrid DEA, network DEA, two-stage DEA, fuzzy DEA, and three-stage DEA.

2.2. Dynamic DEA. Many research studies utilize static analysis, with dynamic DEA window analysis to analyze dynamic models. Färe et al. [36] offer the Malmquist index, but during two periods, the researchers do not analyze the impact of carry-over. Färe and Grosskopf [37] then offer a new analysis of the dynamic impact of consecutive activities. Chen [38] and K. S. Park and K. Park [39] subsequently present SBM studies of several dynamics, with the dynamic analysis model extended into a slack-based measure by Tone and Tsutsui [40]. In order to carry-over activities as a form of connectivity, they propose the SBM (slack-based measures) dynamic DEA model. Tone and Tsutsui [40] develop the model into SBM dynamic analysis, with carry-over activities as a link, and the existence of activities divided into a four-model analysis: (1) desirable ( $\left.Z^{\text {good }}\right)$; (2) undesirable $\left(Z^{\text {bad }}\right) ;(3)$ discretionary $\left(Z^{\text {free }}\right)$; (4) nondiscretionary $\left(Z^{\mathrm{fix}}\right)$, with carry-over variables from period $t$ to period $t+1$. 
The following is the nonoriented model:

$$
\begin{gathered}
\rho_{0}^{*}=\min \frac{(1 / T) \sum_{t=1}^{T} W^{t}\left[1-(1 / m+n \mathrm{bad})\left(\sum_{i=1}^{m}\left(w_{i}^{-} s_{i t}^{-} / x_{i o t}\right)+\sum_{r=1}^{n \mathrm{bad}}\left(s_{i t}^{\mathrm{bad}} / z_{\text {rot }}^{\mathrm{bad}}\right)\right)\right]}{(1 / T) \sum_{t=1}^{T} W^{t}\left[1+(1 / s+n \mathrm{good})\left(\sum_{l=1}^{s}\left(w_{i}^{+} s_{i t}^{+} / y_{i o t}\right)+\sum_{r=1}^{\text {nood }}\left(s_{i t}^{\mathrm{good}} / z_{r o t}^{\mathrm{good}}\right)\right)\right]}, \\
\sum_{r=1}^{n} z_{r j t}^{\alpha} \lambda_{j}^{t}=\sum_{j=1}^{n} z_{r j t}^{\alpha} \lambda_{j}^{t+1}, \quad(\forall i ; t=1, \ldots, T-1) .
\end{gathered}
$$

Equation (2) is the connection equation between $t$ and $t+1$.

$$
\begin{aligned}
& x_{i o t}=\sum_{j=1}^{n} x_{i j t} \lambda_{j}^{t}+s_{i t}^{-}, \quad(i=1, \ldots, m ; t=1, \ldots, T), \\
& x_{i o t}^{\mathrm{fix}}=\sum_{j=1}^{n} x_{i o t}^{\mathrm{fix}} \lambda_{j}^{t}, \quad(i=1, \ldots, p ; t=1, \ldots, T), \\
& y_{\text {lot }}=\sum_{l=1}^{n} y_{l j t} \lambda_{j}^{t}-s_{l t}^{+}, \quad(l=1, \ldots, s ; t=1, \ldots, T), \\
& y_{\text {lot }}^{\mathrm{fix}}=\sum_{l=1}^{n} y_{l o t}^{\mathrm{fix}} \lambda_{j}^{t}, \quad(l=1, \ldots, r ; t=1, \ldots, T), \\
& z_{\text {rot }}^{\text {good }}=\sum_{r=1}^{n} z_{r o t}^{\text {good }} \lambda_{j}^{t}-s_{r t}^{\text {good }}, \quad(r=1, \ldots, n \mathrm{good} ; t=1, \ldots, T), \\
& z_{\text {rot }}^{\mathrm{bad}}=\sum_{r=1}^{n} z_{r j t}^{\mathrm{bad}} \lambda_{j}^{t}+s_{r t}^{\mathrm{bad}}, \quad(r=1, \ldots, n \mathrm{bad} ; t=1, \ldots, T), \\
& z_{r o t}^{\mathrm{free}}=\sum_{r=1}^{n} z_{r j t}^{\mathrm{free}} \lambda_{j}^{t}+s_{r t}^{\mathrm{free}}, \quad(r=1, \ldots, n \mathrm{free} ; t=1, \ldots, T), \\
& z_{r o t}^{\mathrm{fix}}=\sum_{r=1}^{n} z_{r j t}^{\mathrm{fix}} \lambda_{j}^{t}, \quad(r=1, \ldots, n \mathrm{fix} ; t=1, \ldots, T), \\
& \sum_{j=1}^{n} \lambda_{j}^{t}=1 \quad(t=1, \ldots, T), \\
& \lambda_{j}^{t} \geq 0, s_{i t}^{-} \geq 0, s_{l t}^{+} \geq 0, s_{r t}^{\mathrm{good}} \geq 0, s_{r t}^{\mathrm{bad}} \geq 0 \text { and } s_{r t}^{\mathrm{free}}: \text { free }(\forall i, t) .
\end{aligned}
$$

The most efficient solution is

$$
\begin{array}{r}
\rho_{0 t}=\frac{1-(1 / m+n \mathrm{bad})\left(\sum_{i=1}^{m}\left(w_{i}^{-} s_{i o t}^{-*} / x_{i o t}\right)+\sum_{r=1}^{n \mathrm{bad}}\left(s_{\text {rot }}^{\mathrm{bad} *} / z_{\text {rot }}^{\mathrm{bad}}\right)\right)}{1+(1 / s+n \operatorname{good})\left(\sum_{l=1}^{s}\left(w_{i}^{+} s_{i t}^{+*} / y_{l o t}\right)+\sum_{r=1}^{n \text { good }}\left(s_{\text {rot }}^{\mathrm{good} *} / z_{r o t}^{\text {good }}\right)\right)} \\
(i=1, \ldots, T) .
\end{array}
$$

2.3. The Modified Dynamic SBM Model. Since this study considers the undesirable output in the dynamic SBM model, Tone and Tsutsui's [40] dynamic SBM model can be modified to be the undesirable output in the dynamic SBM model. Suppose the observation is a $J(J=1, \ldots, n)$ dimension decision-making unit (DMU) set in which the DMU under evaluation is represented by $\mathrm{DMU}_{O}$ and subject to $\mathrm{DMU}_{O} \in J$. The input and output used to compute the efficiency are labeled as $m$ inputs $x_{i j t}(i=1, \ldots, m)$ and $s$ outputs $Y_{l j t}$, respectively. Let output $Y$ be divided into $\left(Y^{g}\right.$, $Y^{b}$ ), where $Y^{g}$ is the desirable output, $Y^{b}$ is the undesirable output, and $Z^{\text {good }}$ is carried over from period $t$ to period $t+1$. The following is the nonoriented model: 


$$
\theta_{0}^{*}=\min \frac{(1 / T) \sum_{t=1}^{T} W^{t}\left[1-(1 / m) \sum_{i=1}^{m} s_{i t}^{-} / x_{i o t}\right]}{(1 / T) \sum_{t=1}^{T} W^{t}\left[1+\left(1 / s_{1}+s_{2}+n g o o d\right)\left[\sum_{l=1}^{s_{1}} s_{j t}^{+g} / y_{l o t}^{g}+\sum_{l=1}^{s_{2}} s_{j t}^{-b} / y_{l o t}^{b}+\sum_{r=1}^{n g o o d} s_{r t}^{\text {good }} / z_{\text {rot }}^{\text {good }}\right]\right]} .
$$

The following six equations show the connection equation between $t$ and $t+1$ :

$$
\begin{aligned}
& \sum_{j=1}^{n} z_{i j t}^{\alpha} \lambda_{j}^{t}=\sum_{j=1}^{n} z_{i j t}^{\alpha} \lambda_{j}^{t+1}, \quad(\forall i ; t=1, \ldots, T-1), \\
& x_{i o t}=\sum_{i=1}^{m} x_{i j t} \lambda_{i}^{t}+s_{i t}^{-}, \quad(i=1, \ldots, m ; t=1, \ldots, T), \\
& y_{\text {lot }}=\sum_{l=1}^{s 1} y_{\text {lot }}^{+g} \lambda_{j}^{t}-s_{l t}^{+g}, \quad(l=1, \ldots, s 1 ; t=1, \ldots, T), \\
& y_{l o t}=\sum_{l=1}^{s 2} y_{l o t}^{-b} \lambda_{j}^{t}-s_{l t}^{-b}, \quad(l=1, \ldots, s 2 ; t=1, \ldots, T), \\
& z_{\text {rot }}^{\text {good }}=\sum_{r=1}^{n g o o d} z_{\text {rot }}^{\text {good }} \lambda_{j}^{t}-s_{r t}^{\text {good }}, \quad(R=1, \ldots, n g o o d ; t=1, ., T), \\
& \sum_{j=1}^{n} \lambda_{j}^{t}=1 \quad(t=1, \ldots, T), \\
& \lambda_{j}^{t} \geq 0, s_{i t}^{-} \geq 0, s_{l t}^{+g} \geq 0, s_{l t}^{-b} \geq 0, s_{r t}^{\text {good }} \geq 0 .
\end{aligned}
$$

The most efficient solution is

$$
\rho_{0 t}=\frac{1-(1 / m)\left(\sum_{i=1}^{m}\left(s_{i o t}^{-*} / x_{i o t}\right)\right)}{1+(1 / s 1+s 2+n g o o d)\left(\sum_{l=1}^{s 1}\left(s_{j t}^{+g *} / y_{l o t}\right)+\sum_{l=1}^{s 2}\left(s_{j t}^{-b *} / y_{l o t}\right)+\sum_{r=1}^{n g o o d}\left(s_{\text {rot }}^{\text {good } *} / z_{\text {rot }}^{\text {good }}\right)\right)}, \quad(i=1, \ldots, T) .
$$

In equation (5), $W^{t}$ denotes the weight of time and the range of time of this model is from 2012 to 2015. $x_{i o t}$ indicates outputs, which are labor, motor vehicle number, and electricity consumption. $y_{i o t}^{+g}$ denotes desirable output which is disposable income. $y_{i o t}^{-b}$ denotes undesirable outputs, which are $\mathrm{PM}_{2.5}, \mathrm{NO}_{x}$, and $\mathrm{SO}_{2} . Z_{\text {rot }}^{\text {good }}$ is carry over, which is fixed assets. $s_{i t}^{-}$indicates input slack. $s_{j t}^{+g}$ indicates desirable output slack. $s_{j t}^{-b}$ indicates undesirable output slack. $s_{\text {rot }}^{\text {good }}$ indicates undesirable output slack.

This study lists labor, motor vehicle number, and electricity consumption as inputs. Suspended particulate emissions $\left(\mathrm{PM}_{2.5}\right)$, nitrogen oxide emissions $\left(\mathrm{NO}_{2}\right)$, and sulfur oxide emissions $\left(\mathrm{SO}_{2}\right)$ are undesirable outputs. Fixed assets are a carry-over variable. Table 1 lists the details.

The number of motor vehicles, electricity consumption, average disposable income, and $\mathrm{NO}_{2}, \mathrm{SO}_{2}$, and $\mathrm{PM}_{2.5}$ efficiency indices.

$\mathrm{Hu}$ and Wang [19] total-factor energy efficiency index is used to overcome any possible bias in the traditional energy efficiency indicator. For each specific evaluated country, we calculate the number of motor vehicles, electricity consumption, average disposable income, and $\mathrm{NO}_{2}, \mathrm{SO}_{2}$, and $\mathrm{PM}_{2.5}$ efficiencies from the following equations:

the number of motor vehicles' efficiency $=\frac{\text { target motor vehicles' efficiency input }(i, t)}{\text { actual motor vehicles' efficiency input }(i, t)}$,

electricity consumption efficiency $=\frac{\text { target electricity consumption input }(i, t)}{\text { actual electricity consumption input }(i, t)}$, 


$$
\begin{aligned}
& \text { average disposable efficiency }=\frac{\text { actual average disposible income output }(i, t)}{\text { target average disposible output }(i, t)}, \\
& \mathrm{NO}_{2} \text { efficiency }=\frac{\operatorname{target~} \mathrm{NO}_{2} \text { undesirable output }(i, t)}{\operatorname{actual~} \mathrm{NO}_{2} \text { undesirable output }(i, t)}, \\
& \mathrm{PM}_{2.5} \text { efficiency }=\frac{\operatorname{target} \mathrm{PM}_{2.5} \text { undesirable output }(i, t)}{\operatorname{actual~} \mathrm{PM}_{2.5} \text { undesirable output }(i, t)}, \\
& \mathrm{SO}_{2} \text { efficiency }=\frac{\operatorname{target~} \mathrm{SO}_{2} \text { undesirable output }(i, t)}{\operatorname{actual~} \mathrm{SO}_{2} \text { undesirable output }(i, t)} .
\end{aligned}
$$

The efficiency index indicates the ratio of target value and actual value. The target value indicates the most efficient value. Thus, the efficiency index denotes the difference of actual vale and target value. The index (ratio) equals to 1 when the actual value reaches the target value, and the actual value is most efficient. The index is more efficient when the value is close to 1 .

If the target motor vehicle number and electricity consumption input equal the actual inputs and the $\mathrm{NO}_{2}$, $\mathrm{PM}_{2.5}$, and $\mathrm{SO}_{2}$ outputs equal the actual undesirable outputs, then the motor vehicle number, electricity consumption, and $\mathrm{NO}_{2}, \mathrm{PM}_{2.5}$, and $\mathrm{SO}_{2}$ efficiencies equal 1, indicating no room for improvement on their efficiency. The actual value reaches the target. If the target motor vehicle number and electricity consumption inputs are less than the actual input and the $\mathrm{NO}_{2}, \mathrm{PM}_{2.5}$, and $\mathrm{SO}_{2}$ outputs are less than the actual undesirable outputs, then the motor vehicle number, electricity consumption" and $\mathrm{NO}_{2}, \mathrm{PM}_{2.5}$, and $\mathrm{SO}_{2}$ efficiencies are less than 1 , indicating the actual value is inefficiency. There is room for improvement on actual value.

If the target average disposable income output is equal to the actual average disposable income output, then the average disposable income efficiency equals 1 , indicating overall efficiency. If the actual average disposable income output is less than the target average disposable income output, then the average disposable income efficiency is less than 1 , indicating overall inefficiency.

\section{Empirical Results and Analysis}

\subsection{Sources and Variables}

3.1.1. Data Source. This research takes Taiwan as a case study from 2012 to 2015, including New Taipei City, Taipei City, Taoyuan City, Taichung City, Tainan City, Kaohsiung City, Yilan County, Hsinchu County, Miaoli County, Changhua County, Nantou County, Yunlin County, Chiayi County, Pingtung County, Taitung County, Hualien County, Keelung City, Hsinchu City, and Chiayi City. The source is from Taiwan Statistics Department, Taiwan Power Company, and the Environmental Protection Agency of the Executive Yuan. The software used by this research is MaxDEA. This software is a benefit for DEA analysis, especially for model with undesirable output.
3.1.2. Variable and the Structure of Model. This is a dynamic model with several periods, such as period $t$ and period $t+1$. The inputs are labor, motor vehicle number, and electricity consumption. Labor and electricity consumption are used for economic development. Electricity is the main energy consumption of Taiwan. A large amount of air pollutants are generated during the production of electricity (ex: thermal power). Vehicles are a source of air pollutants in daily life.

There are two kinds of output. The desirable output is average disposable income which is an indicator of economic performance. The undesirable outputs are air pollutant which is generated by economic development and citizen's daily life. The carry-over factor which continues to each period (ex: period $t$ to period $t+1$ ) is fixed assets. The linkage of variables is shown in Figure 1.

3.2. Statistics of Input and Output Variables. Table 2 summarizes the statistics of Taiwan's counties and cities from 2012 to 2015. In 2012, the average number of laborers is 569,474 , the maximum is $1,892,000$ in New Taipei City, and the minimum is 103,000 in Taitung County, with a standard deviation of 523,758 . The average number of motor vehicles is $1,166,673$, with a maximum of $3,309,078$ units in $\mathrm{New}$ Taipei City, a minimum of 246,208 units in Taitung County, and a standard deviation of 1,013,652 units. The average electricity consumption is 7.819 billion, the maximum is 22.399 billion in New Taipei City, the minimum is 485.1 million in Taitung County, and the standard deviation is 7.529 billion degrees. The average yearly disposable income is NT\$874,514, the maximum is NT\$1,278,278 in Taipei City, the minimum is NT\$670,017 in Taitung County, and the standard deviation is NT\$158,827. The average amount of suspended particulate emissions is 3,941 metric tons, the maximum is 10,696 metric tons in Kaohsiung City, the minimum is 514 metric tons in Chiayi City, and the standard deviation of 2,631 . The average sulfur oxide emissions are 6,397 metric tons, with a maximum of 42,929 metric tons in Kaohsiung City, a minimum of 60 metric tons in Chiayi City, and a standard deviation of 10,594 metric tons. The average NO $x$ emissions are 20,213 metric tons, with a maximum of 76,826 metric tons in Kaohsiung City, a minimum of 2,281 metric tons in Chiayi City, and a standard deviation of 19,626 metric tons. The average fixed asset investment for a factory is $\mathrm{NT} \$ 56,753,880$ thousand, the maximum value is 
TABle 1: Definitions of variables.

\begin{tabular}{|c|c|c|}
\hline \multicolumn{2}{|r|}{ Variable } & Definition \\
\hline \multirow{3}{*}{ Input } & Labor & $\begin{array}{c}\text { Above fifteen-year-old paid worker or engaged in unpaid family work for more than } 15 \\
\text { hours (unit: person) }\end{array}$ \\
\hline & Motor vehicle number & $\begin{array}{c}\text { Number of motor vehicles with uniform licenses to the supervision authorities at the end of } \\
\text { the year (unit: vehicle) }\end{array}$ \\
\hline & Electricity o & $\begin{array}{c}\text { Electricity sold to the service industry, government schools, agriculture, forestry, fisheries, } \\
\text { and industrial sales (unit: degree) }\end{array}$ \\
\hline Desirable output & $\begin{array}{l}\text { Average disposable } \\
\text { income }\end{array}$ & Disposable income/total number of households (unit: NT\$) \\
\hline \multirow[b]{2}{*}{$\begin{array}{l}\text { Undesirable } \\
\text { output }\end{array}$} & $\begin{array}{l}\text { Suspended particulate } \\
\text { emissions }\end{array}$ & Total emissions of suspended particulates $\left(\mathrm{PM}_{2.5}\right)$ (unit: metric tons) \\
\hline & NO $x$ emissions & $\begin{array}{c}\text { Total emissions of nitrogen oxides (including nitrogen monoxide and nitrogen dioxide) } \\
\text { (unit: metric tons) }\end{array}$ \\
\hline Carry-over & Sulfur oxide emissions & $\begin{array}{l}\text { Total emissions of sulfur oxides (including sulfur dioxide) (unit: metric tons) } \\
\text { The amount of fixed assets newly added by the factory in normal operations, including } \\
\text { equipment investment (antipollution equipment, machinery and equipment, transportation } \\
\text { vehicles, and other equipment), land acquisition, dormitory, factory warehouse office, and } \\
\text { other construction projects (unit: NT } \$ 1,000)\end{array}$ \\
\hline
\end{tabular}

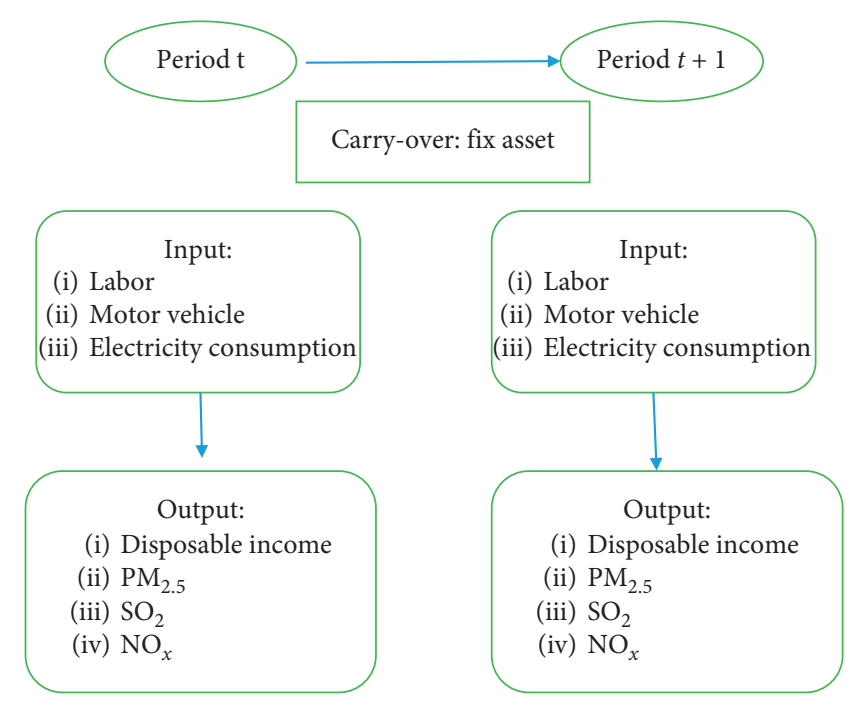

FIGURE 1: The structure of the model.

NT\$199,155,007 thousand in Tainan City, the minimum is NT\$324,609 thousand in Chiayi City, and the standard deviation is NT\$66,919,221 thousand (Figure 2).

According to Table 2, regardless of the amount of labor, motor vehicles, and electricity consumption, the maximum values are mainly concentrated in New Taipei City and Tainan City. The minimum values are mainly concentrated in Taitung County and Chiayi City. For average disposable income, the maximum value in the 4 years is in Taipei City. The minimum values are mainly concentrated in Taitung County and Chiayi City. The maximum emission of suspended particulates is mainly in Kaohsiung City, and the minimum emissions are in Chiayi City. The maximum emissions of sulfur oxides are in Kaohsiung City, and the minimum emissions are in Chiayi City. The maximum fixed asset investment for a factory is in Tainan City, and the minimum value is in Taitung County.
3.3. Empirical Analysis. This study explore the overall efficiency of Taiwan's counties and cities from 2012 to 2015.

3.3.1. Overall Efficiency. As shown in Table 3, the overall efficiency average is 0.8215 , and the average efficiency for each year from 2012 to 2015 is, respectively, 0.8360, 0.7984, 0.8199 , and 0.8370 . The room for improvement is still between $16.3 \%$ and $20.2 \%$. The four-year average efficiency maximum is 1 in Taipei City, Taitung County, Keelung City, Hsinchu City, and Chiayi City. The lowest 4-year average efficiency is in Tainan City. The bottom three rankings are Yunlin County, Changhua County, and Tainan City.

The average efficiency in 2012 is 0.8360 , and the most efficient regions are Taipei City, Taitung County, Keelung City, Hsinchu City, and Chiayi City. The bottom three are Taichung City, Yunlin County, and Tainan City. The average efficiency in 2013 is 0.7984 , and the most efficient are Taipei 


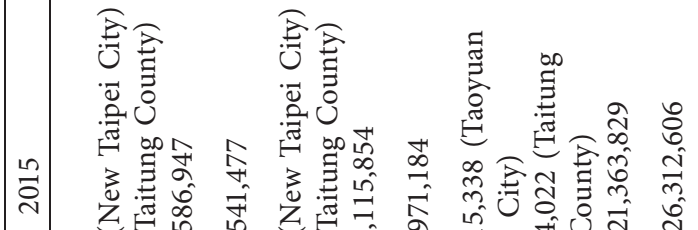

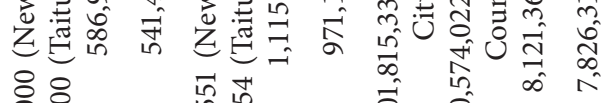

空各

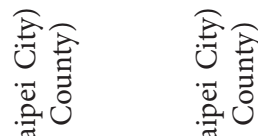

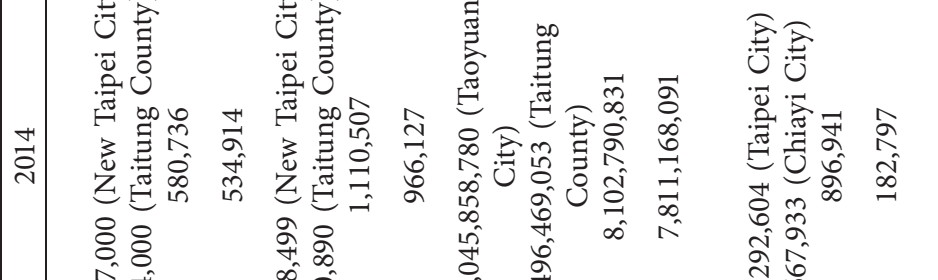

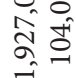

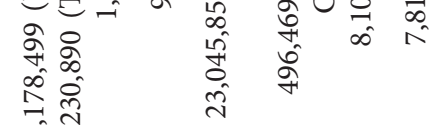

要重高高

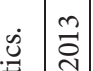

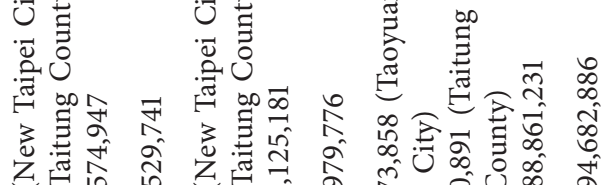

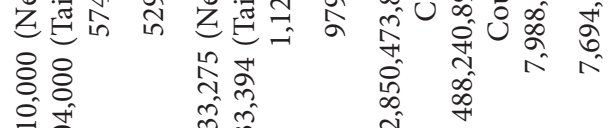

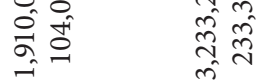

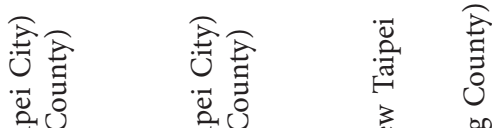

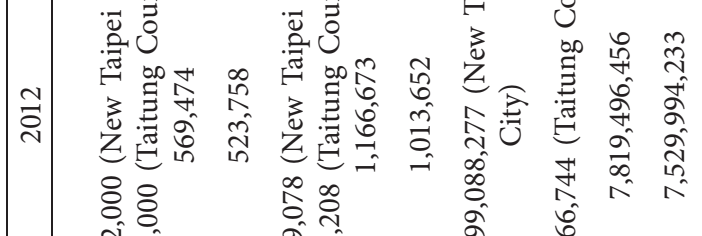

:

क्ष

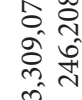

iิ
昰言

तิ

氞言

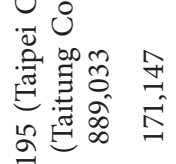

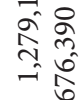

昰言

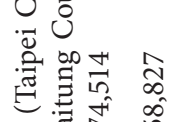

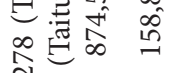

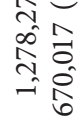

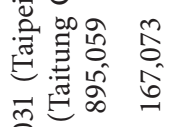

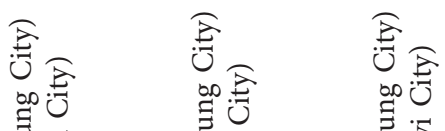

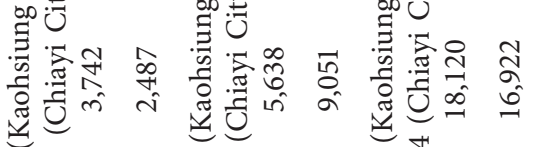

à

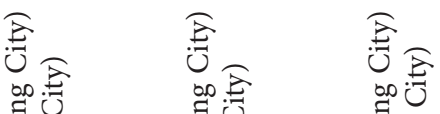

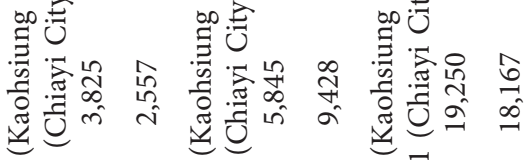

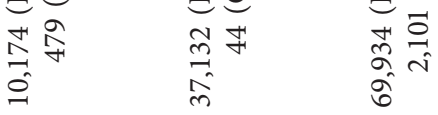

氙

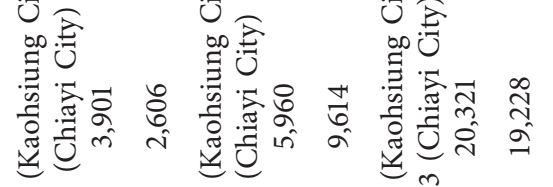

ñ

毒

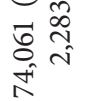

氙在

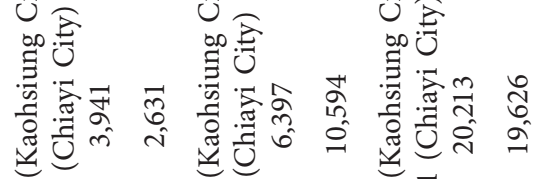

苗

สิ

సิ ๙ิ

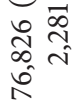

空空

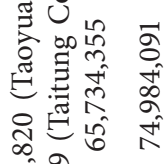

จे ลे

กิ่

氙彥

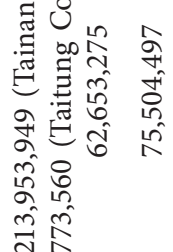

氙育

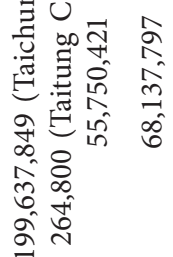


Labor (people)

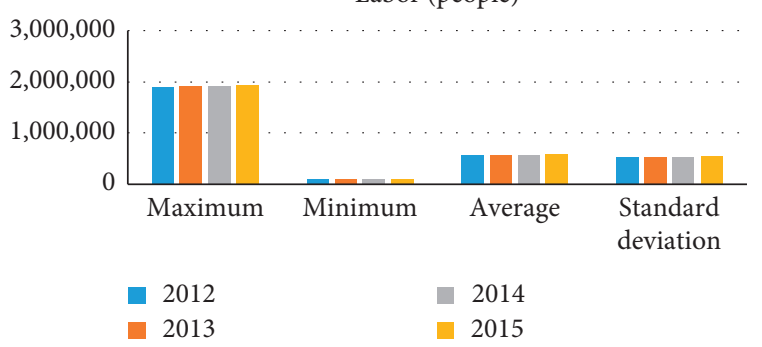

(a)

Electricity consumption (degrees)

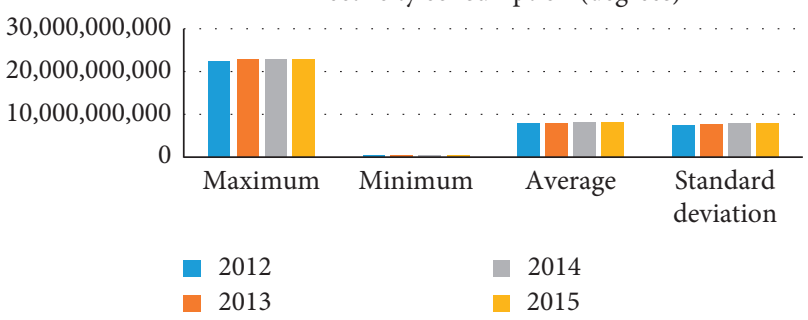

(c)

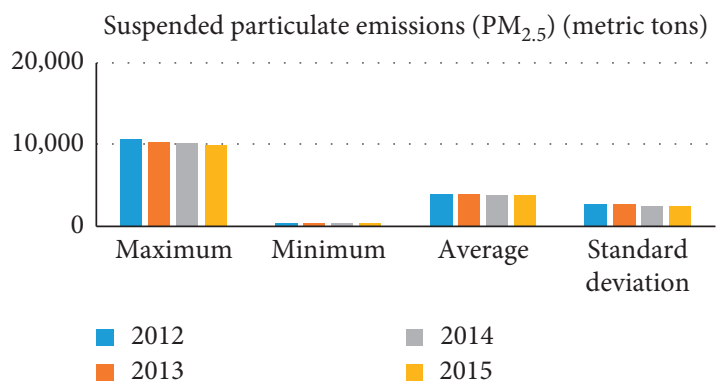

(e)

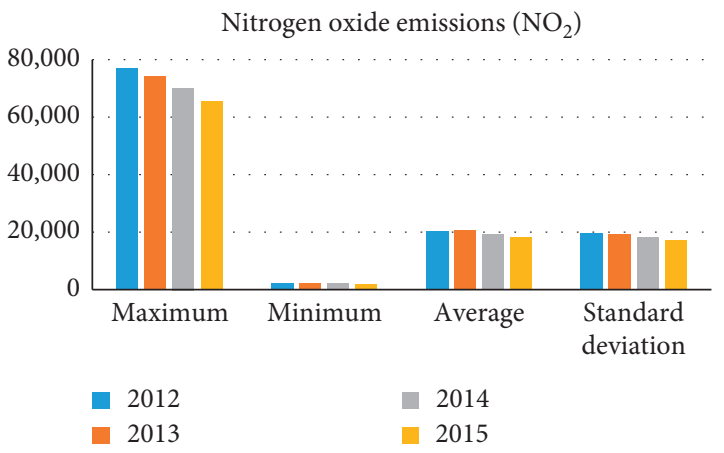

(g)

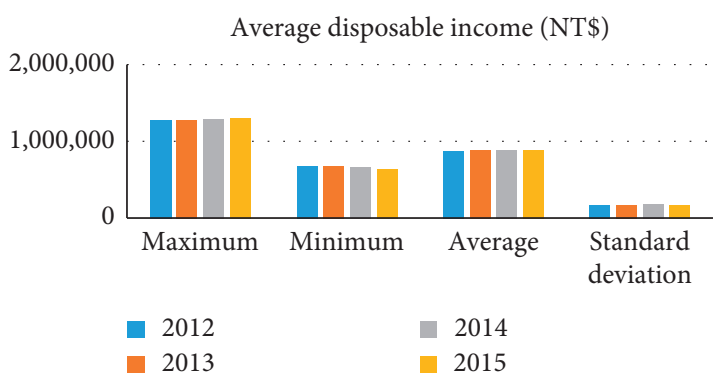

(b)

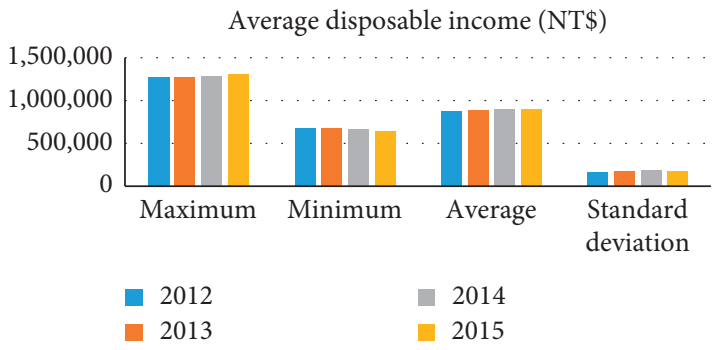

(d)

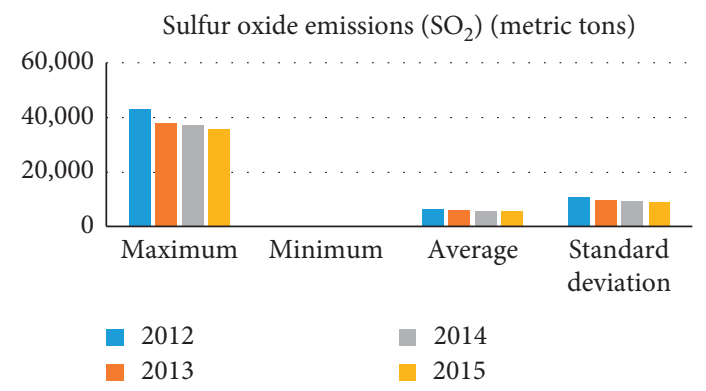

(f)

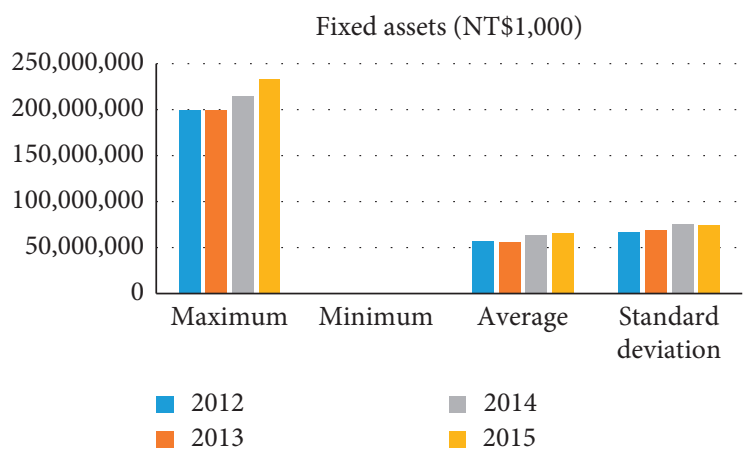

(h)

FIGURE 2: Description of statistics.

City, Taitung County, Keelung City, Hsinchu City, and Chiayi City. The bottom three are Tainan City, Changhua County, and Yunlin County. The average efficiency in 2014 is 0.8199 , with the most efficient being Taipei City, Taitung County, Keelung City, Hsinchu City, and Chiayi City. The average efficiency in 2015 is 0.8370 , with the most efficient being Taipei City, Taitung County, Keelung City, Hsinchu City, and Chiayi City. The bottom three are Yunlin County, Changhua County, and Tainan City. In 2012, the average efficiency of 0.8360 is the highest. In 2013, the average efficiency is 0.7984 , the average efficiency in 2014 is 0.8199 , and the average efficiency in 2015 is 0.8370 . The most efficient are Taipei City, Taitung County, Keelung City, Hsinchu City, and Chiayi City; the worst are Tainan County, Changhua County, and Yunlin County.

3.3.2. Annual Input and Output Variable Efficiencies. From electricity consumption in Table 4, the four-year efficiency value of 1 covers Taipei City, Hsinchu County, Nantou County, Yunlin County, Chiayi County, Pingtung County, Taitung County, Hsinchu City, and Chiayi City. 
TABle 3: Overall efficiency of Taiwan's counties and cities from 2012 to 2015.

\begin{tabular}{|c|c|c|c|c|c|c|}
\hline $\mathrm{DMU}$ & 2012 & 2013 & 2014 & 2015 & Average & Rank \\
\hline New Taipei City & 0.7134 & 0.7280 & 0.7331 & 0.7302 & 0.7261 & 13 \\
\hline Taipei City & 1 & 1 & 1 & 1 & 1 & 1 \\
\hline Taoyuan City & 0.8140 & 0.8134 & 0.8509 & 0.8482 & 0.8312 & 8 \\
\hline Taichung City & 0.6937 & 0.7262 & 0.7393 & 0.7383 & 0.7239 & 14 \\
\hline Tainan City & 0.6242 & 0.6579 & 0.6497 & 0.6649 & 0.6488 & 19 \\
\hline Kaohsiung City & 0.6995 & 0.7155 & 0.7099 & 0.7206 & 0.7113 & 15 \\
\hline Yilan County & 0.9381 & 0.7687 & 0.9077 & 0.9944 & 0.8940 & 7 \\
\hline Hsinchu County & 0.9952 & 0.9048 & 0.9348 & 0.93 & 0.9401 & 6 \\
\hline Miaoli County & 0.7982 & 0.7312 & 0.8411 & 0.7948 & 0.7893 & 9 \\
\hline Changhua County & 0.7037 & 0.6566 & 0.6611 & 0.6671 & 0.6716 & 18 \\
\hline Nantou County & 0.8736 & 0.7083 & 0.7808 & 0.7647 & 0.7775 & 11 \\
\hline Yunlin County & 0.6761 & 0.6365 & 0.6824 & 0.7115 & 0.6756 & 17 \\
\hline Chiayi County & 0.7870 & 0.6899 & 0.6712 & 0.7818 & 0.7287 & 12 \\
\hline Pingtung County & 0.7424 & 0.6687 & 0.6764 & 0.7312 & 0.7032 & 16 \\
\hline Taitung County & 1 & 1 & 1 & 1 & 1 & 1 \\
\hline Hualien County & 0.8255 & 0.7640 & 0.7398 & 0.8251 & 0.7868 & 10 \\
\hline Keelung City & 1 & 1 & 1 & 1 & 1 & 1 \\
\hline Hsinchu City & 1 & 1 & 1 & 1 & 1 & 1 \\
\hline Chiayi City & 1 & 1 & 1 & 1 & 1 & 1 \\
\hline Average value & 0.8360 & 0.7984 & 0.8199 & 0.8370 & 0.8215 & \\
\hline Standard deviation & 0.1347 & 0.1377 & 0.1363 & 0.1284 & 1 & \\
\hline Maximum & 1 & 1 & 1 & 1 & 0.6488 & \\
\hline Minimum & 0.6242 & 0.6365 & 0.6497 & 0.6649 & 0.1312 & \\
\hline
\end{tabular}

TABLE 4: Electricity consumption efficiency of counties and cities in Taiwan from 2012 to 2015.

\begin{tabular}{|c|c|c|c|c|}
\hline \multicolumn{5}{|c|}{ Electricity consumption } \\
\hline DMU & 2012 & 2013 & 2014 & 2015 \\
\hline New Taipei City & 0.879 & 0.8759 & 0.8672 & 0.8676 \\
\hline Taipei City & 1 & 1 & 1 & 1 \\
\hline Taoyuan City & 0.4376 & 0.4312 & 0.4279 & 0.4312 \\
\hline Taichung City & 0.5447 & 0.5229 & 0.5147 & 0.5093 \\
\hline Tainan City & 0.4993 & 0.4856 & 0.4589 & 0.4463 \\
\hline Kaohsiung City & 0.4741 & 0.469 & 0.4716 & 0.4791 \\
\hline Yilan County & 0.7851 & 0.8123 & 0.7012 & 0.8878 \\
\hline Hsinchu County & 1 & 1 & 1 & 1 \\
\hline Miaoli County & 0.8566 & 0.9567 & 0.7435 & 0.8359 \\
\hline Changhua County & 0.9485 & 1 & 0.9369 & 1 \\
\hline Nantou County & 1 & 1 & 1 & 1 \\
\hline Yunlin County & 1 & 1 & 1 & 1 \\
\hline Chiayi County & 1 & 1 & 1 & 1 \\
\hline Pingtung County & 1 & 1 & 1 & 1 \\
\hline Taitung County & 1 & 1 & 1 & 1 \\
\hline Hualien County & 0.5506 & 0.5268 & 0.508 & 0.5954 \\
\hline Keelung City & 1 & 1 & 1 & 1 \\
\hline Hsinchu City & 1 & 1 & 1 & 1 \\
\hline Chiayi City & 1 & 1 & 1 & 1 \\
\hline Average value & 0.8408 & 0.8463 & 0.8226 & 0.8449 \\
\hline Standard deviation & 0.2122 & 0.2207 & 0.2243 & 0.2183 \\
\hline
\end{tabular}

Those with efficiency values below the four-year average of 0.8387 are Taoyuan City, Taichung City, Tainan City, Kaohsiung City, Yilan County, and Hualien County. In 2012, there are 9 counties and cities that need to be adjusted. Among them, Taoyuan City, Kaohsiung City, and Tainan City need the greatest improvement, as their efficiency values are $0.4376,0.4741$, and 0.4376 . The remaining 10 counties and cities have an efficiency value of 1 and do not need to adjust. In 2013, there are 8 counties and cities that need to be adjusted. Among them, Taoyuan City, Kaohsiung City, and Tainan City need the greatest improvement, as their efficiency values are $0.4312,0.4690$, and 0.4586 . The remaining 11 counties and cities have an efficiency value of 1. In 2014, there are 9 counties and cities that need to be adjusted. Among them, Taoyuan City, Kaohsiung City, and Tainan City need the greatest improvement, as their efficiency values are $0.4279,0.4589$, and 0.4716 . The remaining 10 counties and cities have an efficiency value of 1 . In 2015, there are 9 counties and cities that need to be adjusted. Among them, Taoyuan City, Kaohsiung City, and Tainan City need the greatest improvement, as their efficiency values are $0.4312,0.4791$, and 0.4463 . The remaining 10 counties and cities have an efficiency value of 1 .

From Table 5 on motor vehicles, the cities with a fouryear efficiency value of 1 are Taipei City, Taitung County, Keelung City, Hsinchu City, and Chiayi City. Those with efficiency values below the four-year average of 0.8351 are New Taipei City, Taoyuan City, Taichung City, Tainan City, Kaohsiung City, Changhua County, Yunlin County, Chiayi County, and Pingtung County. In 2012, there are 14 counties and cities with motor vehicles that need to be adjusted. Among them, New Taipei City, Kaohsiung City, and Pingtung County need the greatest improvement, as their efficiency values are $0.5610,0.5963$, and 0.6503 . The remaining 5 counties and cities have an efficiency value of 1 . In 2013, there are 14 counties and cities with motor vehicles that need to be adjusted. Among them, New Taipei City, Kaohsiung City, and Pingtung County need the greatest improvement, as their efficiency values are $0.5576,0.6143$, and 0.6587 . The remaining 5 counties and cities have an efficiency value of 1 . In 2014, there are 14 counties and cities with motor vehicles that need to be adjusted. Among them, 
TABle 5: Motor vehicle efficiency in counties and cities of Taiwan from 2012 to 2015 .

\begin{tabular}{lcccc}
\hline \multicolumn{5}{c}{ Motor vehicle } \\
\hline DMU & 2012 & 2013 & 2014 & 2015 \\
New Taipei City & 0.5610 & 0.5576 & 0.5563 & 0.5535 \\
Taipei City & 1 & 1 & 1 & 1 \\
Taoyuan City & 0.7954 & 0.7811 & 0.7759 & 0.7609 \\
Taichung City & 0.6809 & 0.6755 & 0.6640 & 0.6542 \\
Tainan City & 0.6901 & 0.7083 & 0.6974 & 0.6949 \\
Kaohsiung City & 0.5963 & 0.6143 & 0.6156 & 0.6127 \\
Yilan County & 0.9602 & 0.9530 & 0.9365 & 0.9359 \\
Hsinchu County & 0.9584 & 0.9424 & 0.9330 & 0.9222 \\
Miaoli County & 0.8804 & 0.8748 & 0.8673 & 0.8708 \\
Changhua County & 0.7211 & 0.7271 & 0.7215 & 0.7187 \\
Nantou County & 0.8385 & 0.8425 & 0.8417 & 0.8426 \\
Yunlin County & 0.7965 & 0.8094 & 0.8045 & 0.8051 \\
Chiayi County & 0.8267 & 0.8368 & 0.8312 & 0.8342 \\
Pingtung County & 0.6503 & 0.6587 & 0.6652 & 0.6622 \\
Taitung County & 1 & 1 & 1 & 1 \\
Hualien County & 0.9281 & 0.9189 & 0.9424 & 0.9599 \\
Keelung City & 1 & 1 & 1 & 1 \\
Hsinchu City & 1 & 1 & 1 & 1 \\
Chiayi City & 1 & 1 & 1 & 1 \\
Average value & 0.8360 & 0.8369 & 0.8343 & 0.8330 \\
Standard deviation & 0.1460 & 0.1421 & 0.1430 & 0.1454 \\
\hline
\end{tabular}

New Taipei City, Kaohsiung City, and Taichung City need the greatest improvement, as their efficiency values are $0.5563,0.6156$, and 0.6640 . The remaining 5 counties and cities have an efficiency value of 1 . In 2015, there are 14 counties and cities with motor vehicles that need to be adjusted. Among them, New Taipei City, Kaohsiung City, and Taichung City need the greatest improvement, as their efficiency values are $0.5535,0.6127$, and 0.6542 . The remaining 5 counties and cities have an efficiency value of 1 .

From the average disposable income of Table 6, the cities with a four-year efficiency value of 1 are Taipei City, Taitung County, Keelung City, Hsinchu City, and Chiayi City. Those with efficiency values below the four-year average of 0.8228 are New Taipei City, Taichung City, Tainan City, Kaohsiung City, Miaoli County, Changhua County, Nantou County, Yunlin County, Chiayi County, Pingtung County, and Hualien County. In 2012, there are 14 counties and cities that need to be adjusted. Among them, Taichung City, Kaohsiung City, and New Taipei City need the most improvement, as their efficiency values are 0.6937, 0.6995, and 0.7134. The remaining 5 counties and cities have an efficiency value of 1 . In 2013, there are 14 counties and cities that need to be adjusted. Among them, Changhua County, Pingtung County, and Chiayi County need the most improvement, as their efficiency values are $0.6566,0.6687$, and 0.6899 . The remaining 5 counties and cities have an efficiency value of 1 . In 2014, there are 14 counties and cities that need to be adjusted. Among them, Tainan City, Changhua County, and Chiayi County need the most improvement, as their efficiency values are $0.6497,0.6611$, and 0.6712 . The remaining 5 counties and cities have an efficiency value of 1 . In 2015, there are 14 counties and cities that need to be adjusted. Among them, Tainan City, Changhua County, and Yunlin
TABle 6: Average disposable income efficiency of counties and cities in Taiwan from 2012 to 2015.

\begin{tabular}{lcccc}
\hline \multicolumn{5}{c}{ Average disposable income } \\
\hline DMU & 2012 & 2013 & 2014 & 2015 \\
New Taipei City & 0.7134 & 0.728 & 0.7331 & 0.7302 \\
Taipei City & 1 & 1 & 1 & 1 \\
Taoyuan City & 0.814 & 0.8134 & 0.8509 & 0.8482 \\
Taichung City & 0.6937 & 0.7262 & 0.7393 & 0.7383 \\
Tainan City & 0.6242 & 0.6579 & 0.6497 & 0.6649 \\
Kaohsiung City & 0.6995 & 0.7155 & 0.7099 & 0.7206 \\
Yilan County & 0.9381 & 0.7687 & 0.9077 & 0.9944 \\
Hsinchu County & 0.9952 & 0.9048 & 0.9348 & 0.93 \\
Miaoli County & 0.7982 & 0.7312 & 0.8411 & 0.7948 \\
Changhua County & 0.7037 & 0.6566 & 0.6611 & 0.6671 \\
Nantou County & 0.8736 & 0.7083 & 0.7808 & 0.7647 \\
Yunlin County & 0.6761 & 0.6365 & 0.6824 & 0.7115 \\
Chiayi County & 0.787 & 0.6899 & 0.6712 & 0.7818 \\
Pingtung County & 0.7424 & 0.6687 & 0.6764 & 0.7312 \\
Taitung County & 1 & 1 & 1 & 1 \\
Hualien County & 0.8255 & 0.764 & 0.7398 & 0.8251 \\
Keelung City & 1 & 1 & 1 & 1 \\
Hsinchu City & 1 & 1 & 1 & 1 \\
Chiayi City & 1 & 1 & 1 & 1 \\
Average value & 0.836 & 0.7984 & 0.8199 & 0.837 \\
Standard deviation & 0.1311 & 0.134 & 0.1327 & 0.125 \\
\hline
\end{tabular}

County need the most improvement, as their efficiency values are $0.6649,0.6671$, and 0.7115 . The remaining 5 counties and cities have an efficiency value of 1 .

3.3.3. Annual $\mathrm{PM}_{2.5}, \mathrm{SO}_{2}$, and $\mathrm{NO}_{2}$ Efficiencies. From Table 7 on $\mathrm{PM}_{2.5}$, the cities with a four-year efficiency value of 1 are Taipei City, Taitung County, Keelung City, Hsinchu City, and Chiayi City. Those with efficiency values below the fouryear average 0.4362 are Taipei City, Taoyuan City, Taichung City, Tainan City, Kaohsiung City, Yilan County, Hsinchu County, Miaoli County, Changhua County, Nantou County, Yunlin County, Chiayi County, Pingtung County, and Hualien County. In 2012, there are 14 counties and cities that need to make adjustments for suspended particulate emissions. Hualien County, Kaohsiung City, and Yilan County need the greatest improvement, as their efficiency values are $0.0874,0.1609$, and 0.1969 . The remaining 5 counties and cities have an efficiency value of 1 . In 2013, there are 14 counties and cities that need to make adjustments for suspended particulate emissions. Hualien County, Kaohsiung City, and Yilan County need the greatest improvement, as their efficiency values are $0.0852,0.1615$, and 0.1644 . The remaining 5 counties and cities have an efficiency value of 1 . In 2014, there are 14 counties and cities that need to make adjustments for suspended particulate emissions. Hualien County, Kaohsiung City, and Yilan County need the greatest improvement, as their efficiency values are 0.0840 , 0.1616 , and 0.1673 . The remaining 5 counties and cities have an efficiency value of 1 . In 2015, there are 14 counties and cities that need to make adjustments for suspended particulate emissions. Hualien County, Kaohsiung City, and Yilan County need the greatest improvement, as their 
TABLE 7: $\mathrm{PM}_{2.5}$ emission efficiency in counties and cities of Taiwan from 2012 to 2015 .

\begin{tabular}{|c|c|c|c|c|}
\hline \multicolumn{5}{|c|}{$\mathrm{PM}_{2.5}$} \\
\hline DMU & 2012 & 2013 & 2014 & 2015 \\
\hline New Taipei City & 0.3001 & 0.2960 & 0.2970 & 0.2981 \\
\hline Taipei City & 1 & 1 & 1 & 1 \\
\hline Taoyuan City & 0.2493 & 0.2475 & 0.2535 & 0.2568 \\
\hline Taichung City & 0.2111 & 0.1964 & 0.1981 & 0.2016 \\
\hline Tainan City & 0.2585 & 0.2499 & 0.2504 & 0.2534 \\
\hline Kaohsiung City & 0.1609 & 0.1615 & 0.1616 & 0.1635 \\
\hline Yilan County & 0.1969 & 0.1644 & 0.1673 & 0.1671 \\
\hline Hsinchu County & 0.4408 & 0.4068 & 0.4029 & 0.4078 \\
\hline Miaoli County & 0.2752 & 0.2552 & 0.2526 & 0.2545 \\
\hline Changhua County & 0.2788 & 0.2940 & 0.3004 & 0.3034 \\
\hline Nantou County & 0.2243 & 0.2224 & 0.2214 & 0.2211 \\
\hline Yunlin County & 0.2175 & 0.2028 & 0.2032 & 0.2068 \\
\hline Chiayi County & 0.2818 & 0.2788 & 0.2785 & 0.2806 \\
\hline Pingtung County & 0.1992 & 0.1803 & 0.1800 & 0.1800 \\
\hline Taitung County & 1 & 1 & 1 & 1 \\
\hline Hualien County & 0.0874 & 0.0852 & 0.0840 & 0.0829 \\
\hline Keelung City & 1 & 1 & 1 & 1 \\
\hline Hsinchu City & 1 & 1 & 1 & 1 \\
\hline Chiayi City & 1 & 1 & 1 & 1 \\
\hline Average value & 0.4411 & 0.4337 & 0.4343 & 0.4357 \\
\hline Standard deviation & 0.3405 & 0.3444 & 0.3441 & 0.3434 \\
\hline
\end{tabular}

efficiency values are $0.0829,0.1635$, and 0.1671 . The remaining 5 counties and cities have an efficiency value of 1 .

From Table 8 on $\mathrm{SO}_{2}$, the cities with a four-year efficiency value of 1 are Taipei City, Taitung County, Keelung City, Hsinchu City, and Chiayi City. Those with efficiency values below the four-year average of 0.3288 are New Taipei City, Taoyuan City, Taichung City, Tainan City, Kaohsiung City, Yilan County, Hsinchu County, Miaoli County, Changhua County, Nantou County, Yunlin County, Chiayi County, Pingtung County, and Hualien County. In 2012, 14 counties and cities need to make adjustments for sulfur oxide emissions. Hualien County, Yunlin County, and Taichung City need the greatest improvement, as their efficiency values are $0.0188,0.0209$, and 0.0207 . The remaining 5 counties and cities have an efficiency value of 1 . In 2013, 14 counties and cities need to make adjustments for sulfur oxide emissions. Kaohsiung City, Hualien County, and Yunlin County need the greatest improvement, as their efficiency values are $0.0108,0.0125$, and 0.0145 . The remaining 5 counties and cities have an efficiency value of 1 . In 2014, 14 counties and cities need to make adjustments for sulfur oxide emissions. Kaohsiung City, Hualien County, and Yunlin County need the greatest improvement, as their efficiency values are $0.0109,0.0128$, and 0.0144 . The remaining 5 counties and cities have an efficiency value of 1 . In 2015,14 counties and cities need to make adjustments for sulfur oxide emissions. Kaohsiung City, Hualien County, and Yunlin County need the greatest improvement, as their efficiency values are $0.0112,0.0131$, and 0.0145 . The remaining 5 counties and cities have an efficiency value of 1 .

From Table 9 on $\mathrm{NO}_{2}$, the cities with a four-year efficiency value of 1 are Taipei City, Taitung County, Keelung City, Hsinchu City, and Chiayi City. Those with efficiency
TABLE 8: $\mathrm{SO}_{2}$ emission efficiency in counties and cities of Taiwan from 2012 to 2015 .

\begin{tabular}{|c|c|c|c|c|}
\hline \multicolumn{5}{|c|}{$\mathrm{SO}_{2}$} \\
\hline DMU & 2012 & 2013 & 2014 & 2015 \\
\hline New Taipei City & 0.1582 & 0.1034 & 0.1083 & 0.1070 \\
\hline Taipei City & 1 & 1 & 1 & 1 \\
\hline Taoyuan City & 0.0691 & 0.0512 & 0.0499 & 0.0487 \\
\hline Taichung City & 0.0270 & 0.0174 & 0.0176 & 0.0179 \\
\hline Tainan City & 0.1424 & 0.1029 & 0.1007 & 0.0990 \\
\hline Kaohsiung City & 0.0152 & 0.0108 & 0.0109 & 0.0112 \\
\hline Yilan County & 0.1061 & 0.0845 & 0.0836 & 0.0811 \\
\hline Hsinchu County & 0.2572 & 0.2355 & 0.2234 & 0.2141 \\
\hline Miaoli County & 0.1495 & 0.1469 & 0.1418 & 0.1385 \\
\hline Changhua County & 0.1616 & 0.1238 & 0.1200 & 0.1170 \\
\hline Nantou County & 0.3198 & 0.2534 & 0.2480 & 0.2452 \\
\hline Yunlin County & 0.0209 & 0.0145 & 0.0144 & 0.0145 \\
\hline Chiayi County & 0.0755 & 0.0505 & 0.0506 & 0.0509 \\
\hline Pingtung County & 0.2748 & 0.2190 & 0.2150 & 0.2120 \\
\hline Taitung County & 1 & 1 & 1 & 1 \\
\hline Hualien County & 0.0188 & 0.0125 & 0.0128 & 0.0131 \\
\hline Keelung City & 1 & 1 & 0.0010 & 1 \\
\hline Hsinchu City & 1 & 1 & 1 & 1 \\
\hline Chiayi City & 1 & 1 & 1 & 1 \\
\hline Average value & 0.3577 & 0.3382 & 0.2841 & 0.3353 \\
\hline Standard deviation & 0.3927 & 0.4017 & 0.3765 & 0.4027 \\
\hline
\end{tabular}

TABLE 9: $\mathrm{NO}_{2}$ emission efficiency of counties and cities in Taiwan from 2012 to 2015.

\begin{tabular}{|c|c|c|c|c|}
\hline \multicolumn{5}{|c|}{$\mathrm{NO}_{2}$} \\
\hline DMU & 2012 & 2013 & 2014 & 2015 \\
\hline New Taipei City & 0.3447 & 0.3223 & 0.3229 & 0.3280 \\
\hline Taipei City & 1 & 1 & 1 & 1 \\
\hline Taoyuan City & 0.2440 & 0.2026 & 0.1996 & 0.2018 \\
\hline Taichung City & 0.1934 & 0.1663 & 0.1664 & 0.1721 \\
\hline Tainan City & 0.4033 & 0.3424 & 0.3432 & 0.3508 \\
\hline Kaohsiung City & 0.1483 & 0.1329 & 0.1324 & 0.1365 \\
\hline Yilan County & 0.2522 & 0.2310 & 0.2213 & 0.2131 \\
\hline Hsinchu County & 0.4329 & 0.4256 & 0.2981 & 0.4148 \\
\hline Miaoli County & 0.2550 & 0.2330 & 0.2255 & 0.2228 \\
\hline Changhua County & 0.0004 & 0.3497 & 0.3463 & 0.3502 \\
\hline Nantou County & 0.5437 & 0.4853 & 0.4846 & 0.4895 \\
\hline Yunlin County & 0.1582 & 0.1450 & 0.1383 & 0.1352 \\
\hline Chiayi County & 0.3021 & 0.2584 & 0.2527 & 0.2521 \\
\hline Pingtung County & 0.3970 & 0.3575 & 0.3545 & 0.3558 \\
\hline Taitung County & 1 & 1 & 1 & 1 \\
\hline Hualien County & 0.1322 & 0.1289 & 0.1225 & 0.1166 \\
\hline Keelung City & 1 & 1 & 1 & 1 \\
\hline Hsinchu City & 1 & 1 & 1 & 1 \\
\hline Chiayi City & 1 & 1 & 1 & 1 \\
\hline Average value & 0.4635 & 0.4622 & 0.4531 & 0.4600 \\
\hline Standard deviation & 0.3419 & 0.3347 & 0.3383 & 0.3365 \\
\hline
\end{tabular}

values below the four-year average 0.4597 are New Taipei City, Taoyuan City, Taichung City, Tainan City, Kaohsiung City, Yilan County, Hsinchu County, Miaoli County, Changhua County, Nantou County, Yunlin County, Chiayi County, Pingtung County, and Hualien County. In 2012, there are 14 counties and cities that need to make adjustments in NOx emissions. Hualien County, Kaohsiung City, and Yunlin County need the greatest improvement, as their 


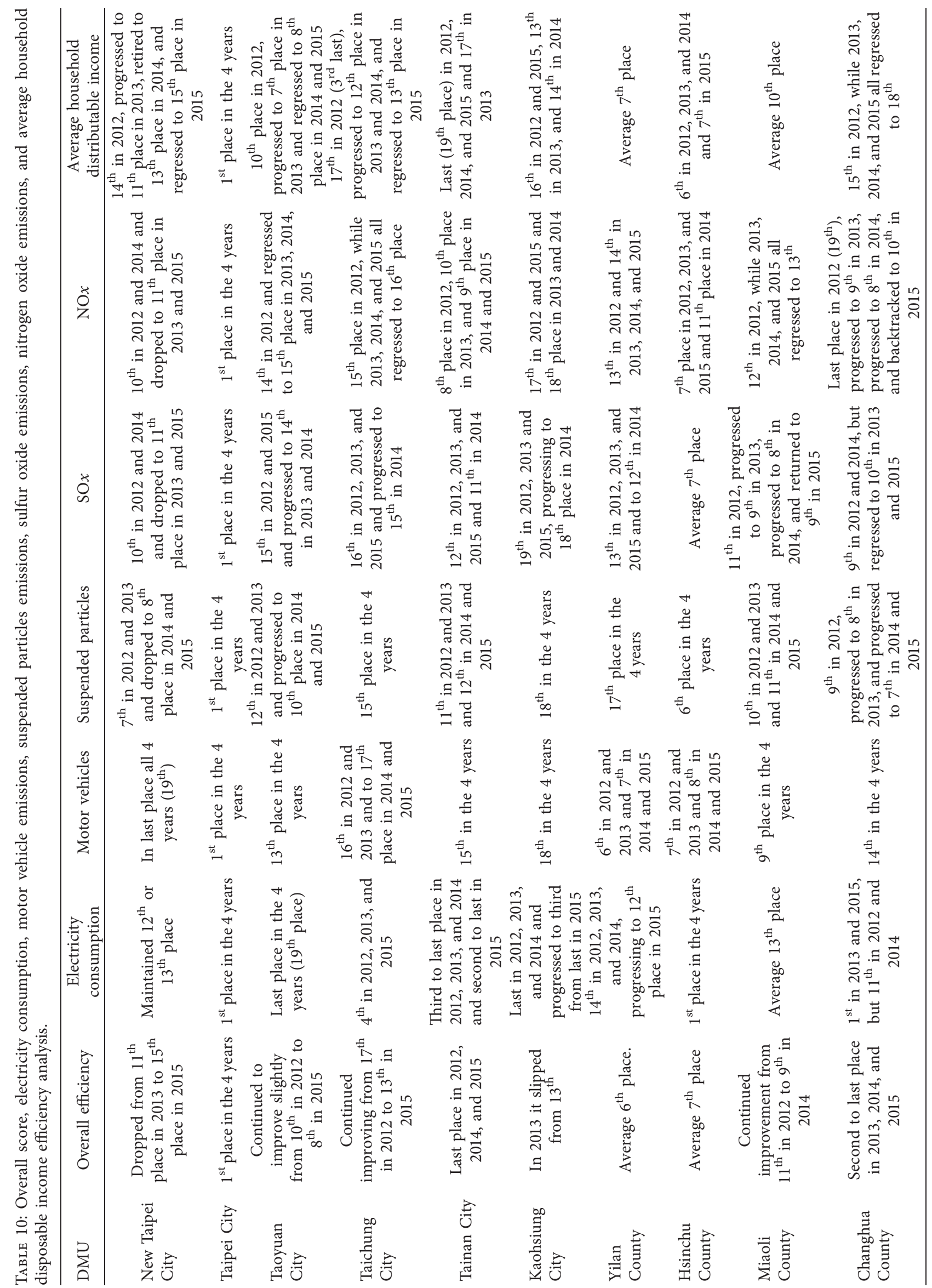




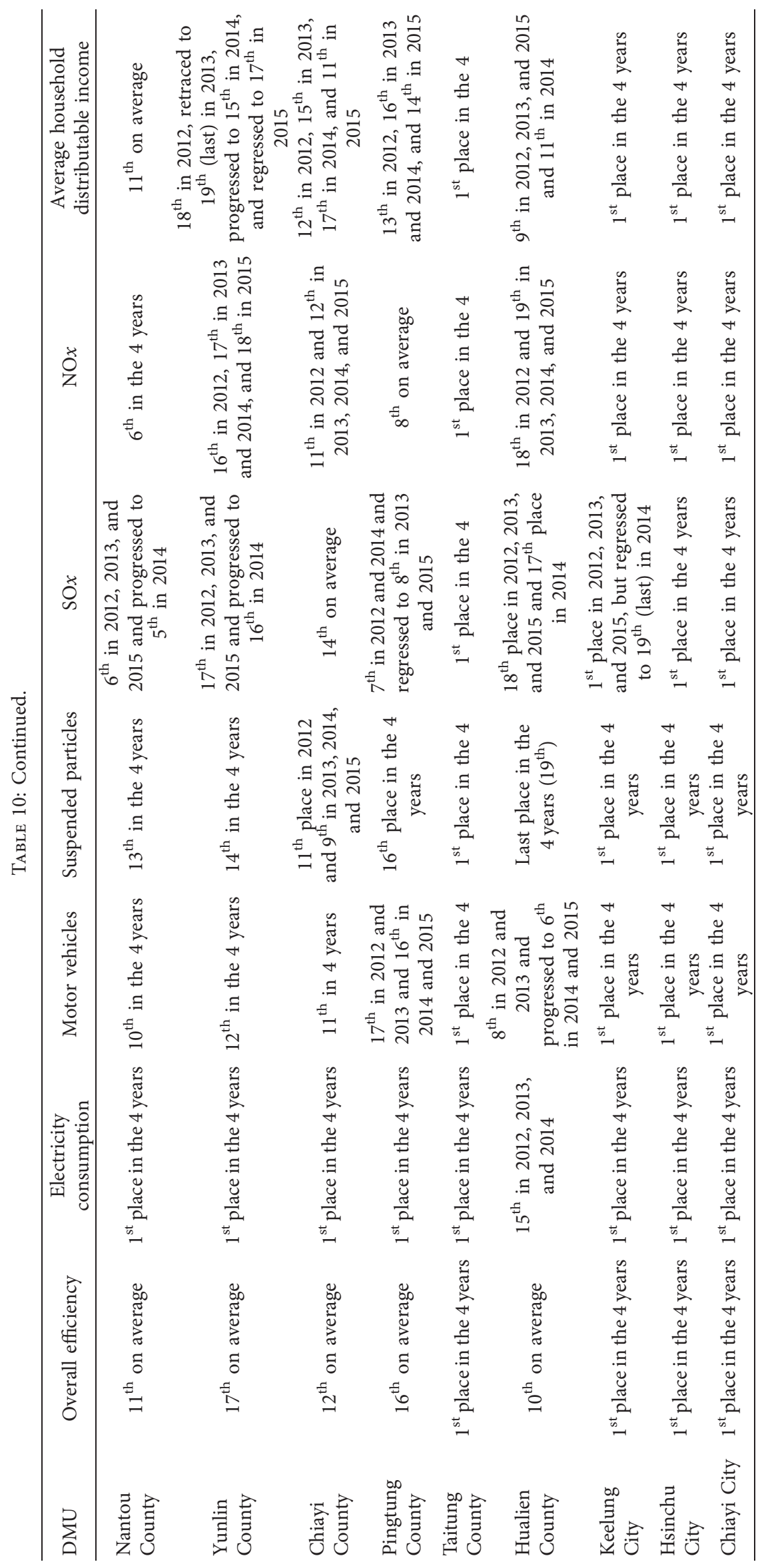


efficiency values are $0.1322,0.1483$, and 0.1582 . The remaining 5 counties and cities have an efficiency value of 1 . In 2013, there are 14 counties and cities that need to make adjustments in NOx emissions. Hualien County, Kaohsiung City, and Yunlin County need the greatest improvement, as their efficiency values are $0.1289,0.1329$, and 0.1450 . The remaining 5 counties and cities have an efficiency value of 1 . In 2014, there are 14 counties and cities that need to make adjustments in NOx emissions. Hualien County, Kaohsiung City, and Yunlin County need the greatest improvement, as their efficiency values are $0.1225,0.1324$, and 0.2213 . The remaining 5 counties and cities have an efficiency value of 1 . In 2015, there are 14 counties and cities that need to make adjustments in NOx emissions. Hualien County, Yunlin County, and Kaohsiung City need the greatest improvement, as their efficiency values are $0.1166,0.1352$, and 0.1365 . The remaining 5 counties and cities have an efficiency value of 1 .

In order to further understand the counties' and cities' electricity consumption, motor vehicles, aerosol emissions, sulfur oxide emissions, nitrogen oxide emissions, and average disposable income per household, this research offers Table 10 for illustration. From Table 10, Taipei City, Taitung County, Hsinchu City, Chiayi City, and Keelung City maintain the highest efficiency values in the 4 years, regardless of overall score, electricity consumption, motor vehicles, fine aerosol emissions, nitrogen oxide emissions, and average per efficiency analysis of household disposable income. From the efficiency analysis of sulfur oxide emissions, Taipei City, Taitung County, Hsinchu City, and Chiayi City still rank first in 4 years. Keelung City also maintains first place in 2012, 2013, and 2015, but in 2014, it ranks $19^{\text {th }}$ (last). In 2014, the Keelung Port Art Exhibition attracted a large number of people from other counties and cities, and the air pollution was serious.

The $19^{\text {th }}$ overall score (last place) is Tainan City. The electricity efficiency value of Tainan City is also in second to last place or third from last place. Its value for motor vehicle efficiency remains in $15^{\text {th }}$ place in the 4 years $\left(5^{\text {th }}\right.$ from last). For its efficiencies of suspended particulate emissions and sulfur oxide emissions, it maintains $11^{\text {th }}$ or $12^{\text {th }}$ place in the 4 years. The average efficiency of each household's disposable income is last place in 2012, 2014, and 2015 (19 th $^{\text {th }}$ place). In 2013 , it improves slightly to $17^{\text {th }}$ (third from last place).

Among the six municipalities, only Taipei City and Taoyuan City rank first and eighth. The remaining $4 \mathrm{mu}-$ nicipalities have poor overall scores. In last place $\left(19^{\text {th }}\right)$ is Tainan City, $15^{\text {th }}$ is Kaohsiung City, $14^{\text {th }}$ is Taichung City, and $13^{\text {th }}$ is New Taipei City.

Among the 13 nonmunicipalities with low overall scores, $18^{\text {th }}$ is Changhua County (second lowest), $17^{\text {th }}$ is Yunlin County (third lowest), $16^{\text {th }}$ is Pingtung County, and $12^{\text {th }}$ is Chiayi County. For nonmunicipalities with middle overall scores, $6^{\text {th }}$ is Hsinchu County, $7^{\text {th }}$ is Yilan County, $9^{\text {th }}$ is Miaoli County, $10^{\text {th }}$ is Hualien County, and $11^{\text {th }}$ is Nantou County.

For the efficiency of electricity consumption, in last place is Taoyuan City for all 4 years. For the efficiency of motor vehicles, in last place is New Taipei City and in $18^{\text {th }}$ is Kaohsiung City for the 4 years (second to last place). For the efficiency of suspended matter emissions, in last place is Hualien County, in $18^{\text {th }}$ is Kaohsiung City (second lowest), in $17^{\text {th }}$ is Yilan County (third from last), and Pingtung County is in $16^{\text {th }}$ place in the 4 years. The undesirable output and desirable output of each county and city have different degrees of progress or regression in the 4 years.

We note that Taipei City, Taitung County, Hsinchu City, Chiayi City, and Keelung City have the best performances. The rest of the counties and cities have a lot of room for improvement. Taiwan's local governments thus should formulate strong policy interventions in air pollution.

\section{Conclusions}

During the current situation of global warming and deteriorating environmental conditions, countries around the world are thinking about how to balance economic growth, reduce environmental pollution, and move forward in the direction of sustainable development. Therefore, this article collects data from 19 counties and cities in Taiwan from 2012 to 2015, using the modified dynamic SBM model to explore the change in efficiency of air pollutants in various regions of the country from the economic perspective. The results are as follows:

(1) From 2012 to 2015, the counties with the best overall efficiency performance are Taipei City, Taitung County, Keelung City, Hsinchu City, and Chiayi City. Their average overall efficiency value is 1 . The average overall efficiency performances are poor in Tainan City, Changhua County, Yunlin County, Pingtung County, and Kaohsiung City, with efficiency values of $0.6488,0.6716,0.6756,0.7032$, and 0.7113 . In counties and cities with the best overall performance and poor performance, the average disposable income per household has no significant relationship with air pollutant emissions.

(2) In the counties and cities with better overall efficiency from 2012 to 2015, the efficiency values of motor vehicles, average household disposable income, and three air pollutant emissions are all 1. Counties and cities with poor performance have large room for improvement in average disposable income per household.

(3) Regarding the undesirable output of suspended particulate emissions, sulfur oxide emissions, and nitrogen oxide emissions, the efficiency values of Taipei City, Taitung County, Keelung City, Hsinchu City, and Chiayi City are all 1 . The efficiency values of the three air pollutants in the remaining 14 counties and cities are far below 0.5, indicating that the air pollution situation there is in urgent need of improvement.

(4) The five counties and cities with the lowest electricity consumption efficiency are Taoyuan City, Kaohsiung City, Tainan City, Taichung City, and Hualien County. The cement industry, mining industry, and tourism industry are concentrated in Hualien 
County and need to improve their efficiency. Due to the high demand for industrial electricity, Taoyuan City accounts for more than half of all electricity in Taiwan. The authority must increase the utilization rate of energy use.

Compared with advanced countries, Taiwan has fallen far behind in air pollution control. The prevention of air pollution still only focuses on propaganda and should change to enforcement as soon as possible. More detailed regulations of pollution reduction in different industries are also necessary. This study has pointed out that the efficiency values of the three air pollutants in fourteen counties and cities are far below 0.5 . Among the six municipalities directly under the central government with relatively high financial autonomy, only Taipei City and Taoyuan City have higher overall scores. The remaining 4 municipalities of Tainan City, Kaohsiung City, Taichung City, and New Taipei City have poor overall scores. Taiwan must pay attention to the future adjustment of its energy structure such as the use of coal and petrochemical energy and renewable energy development policies. Lastly, Taiwan should face the problem of air pollution without dividing the political parties in order to achieve a steady economy and sustainable development for all involved.

By above results, this research provides the following policy recommendation:

(1) Air pollutants move with air flow; thus, the issue of air pollution should be jointly treated with surrounding countries

(2) Local governments reduce coal use to generate electricity to reduce air pollution

(3) Public sector and private sector should replace petrochemical energy with renewable energy to reduce air pollution

(4) The government encourages the public sector and the private sector to use electric vehicles to reduce air pollutant emission by vehicle

\section{Data Availability}

The data used to support the findings of this study are included within the article.

\section{Conflicts of Interest}

The authors declare that there are no conflicts of interest.

\section{References}

[1] World Health Organization, https://www.who.int.

[2] J. Wu, L. Lv, J. Sun, and X. Ji, "A comprehensive analysis of China's regional energy saving and emission reduction efficiency: from production and treatment perspectives," Energy Policy, vol. 84, pp. 166-176, 2015.

[3] B. Lin and K. Du, "Energy and $\mathrm{CO}_{2}$ emissions performance in China's regional economies: do market-oriented reforms matter?" Energy Policy, vol. 78, pp. 113-124, 2014.
[4] K. Wang, Y.-M. Wei, and X. Zhang, "Energy and emissions efficiency patterns of Chinese regions: a multi-directional efficiency analysis," Applied Energy, vol. 104, pp. 105-116, 2013.

[5] Y. Li, L. Sun, T. Feng, and C. Zhu, "How to reduce energy intensity in China: a regional comparison perspective," Energy Policy, vol. 61, pp. 513-522, 2013.

[6] T. Zhang, "Frame work of data envelopment analysis-a model to evaluate the environmental efficiency of China's industrial sectors," Biomedical and Environmental Sciences, vol. 22, no. 1, pp. 8-13, 2009.

[7] K. Wang, S. Yu, and W. Zhang, "China's regional energy and environmental efficiency: a DEA window analysis based dynamic evaluation," Mathematical and Computer Modelling, vol. 58, no. 5-6, pp. 1117-1127, 2013.

[8] G.-B. Bi, W. Song, P. Zhou, and L. Liang, "Does environmental regulation affect energy efficiency in China's thermal power generation? Empirical evidence from a slacks-based DEA model," Energy Policy, vol. 66, pp. 537-546, 2014.

[9] A. Üstün, "Evaluating environmental efficiency of Turkish cities by data envelopment analysis," Global NEST Journal, vol. 17, pp. 281-290, 2015.

[10] X. Liu and J. Liu, "Measurement of low carbon economy efficiency with a three-stage data envelopment analysis: a comparison of the largest twenty $\mathrm{CO}_{2}$ emitting countries," International Journal of Environmental Research and Public Health, vol. 13, no. 11, pp. 1116-1130, 2016.

[11] R. Mavi and C. Standing, "Evaluating eco-innovation of OECD countries with data envelopment analysis," in Proceedings of the International Conferences ITS, Zagreb, Croatia, June 2016.

[12] L. Wen and E. Zhang, "Allocation of $\mathrm{CO}_{2}$ emissions with zero sum gains data envelopment analysis models," Nature Environment and Pollution Technology, vol. 15, pp. 1065-1069, 2016.

[13] X. Yao, C. Guo, S. Shao, and Z. Jiang, "Total-factor $\mathrm{CO}_{2}$ emission performance of China's provincial industrial sector: a meta-frontier non-radial Malmquist index approach," $A p$ plied Energy, vol. 184, pp. 1142-1153, 2016.

[14] K. Du, C. Xie, and X. Ouyang, "A comparison of carbon dioxide $\left(\mathrm{CO}_{2}\right)$ emission trends among provinces in China," Renewable and Sustainable Energy Reviews, vol. 73, pp. 19-25, 2017.

[15] Q. Qin, X. Li, L. Li, W. Zhen, and Y.-M. Wei, “Air emissions perspective on energy efficiency: an empirical analysis of China's coastal areas," Applied Energy, vol. 185, pp. 604-614, 2017.

[16] J. Yi, "Study on carbon emission efficiency of China's industrial industry and analysis of its influencing factors," Low Carbon Economy, vol. 8, no. 1, pp. 20-30, 2017.

[17] Q. Feng, Q. Qiu, Y. Quan, and L. Tang, "Sustainability efficiency of Chinese cities involving coal-fired power plants with data envelopment analysis," International Journal of Sustainable Development \& World Ecology, vol. 24, no. 5, pp. 395-400, 2017.

[18] C. Feng, H. Zhang, and J.-B. Huang, "The approach to realizing the potential of emissions reduction in China: an implication from data envelopment analysis," Renewable and Sustainable Energy Reviews, vol. 71, pp. 859-872, 2017.

[19] J.-L. Hu and S.-C. Wang, "Total-factor energy efficiency of regions in China," Energy Policy, vol. 34, no. 17, pp. 32063217, 2006.

[20] C. Martínez, "Energy efficiency development in German and Colombian non-energy-intensive sectors: a non-parametric analysis," Energy Efficiency, vol. 4, pp. 115-131, 2011. 
[21] T. Sueyoshi and Y. Yuan, "China's regional sustainability and diversified resource allocation: DEA environmental assessment on economic development and air pollution," Energy Economics, vol. 49, pp. 239-256, 2015.

[22] Y.-R. Ma, Q. Ji, and Y. Fan, "Spatial linkage analysis of the impact of regional economic activities on $\mathrm{PM}_{2.5}$ pollution in China," Journal of Cleaner Production, vol. 139, pp. 11571167, 2016.

[23] J. Li, L. Gong, Z. Chen, L. Zeng, G. Yang, and J. Zhang, "The hierarchy and transition of China's urban energy efficiency," Energy Procedia, vol. 104, pp. 110-117, 2016.

[24] J. Choi and D. Roberts, "Impacts of air pollution on productivity growth in the air and truck transportation industries in the US: an application of the data envelopment analysis malmquist environmental productivity index," Open Journal of Social Sciences, vol. 3, pp. 120-129, 2015.

[25] F. D. C. Camioto, H. F. Moralles, E. B. Mariano, and D. A. D. N. Rebelatto, "Energy efficiency analysis of G7 and BRICS considering total-factor structure," Journal of Cleaner Production, vol. 122, pp. 67-77, 2016.

[26] G. Halkos and M. Polemis, The Good, the Bad and the Ugly? Balancing Environmental and Economic Impacts towards Efficiency, pp. 72132-72260, MPRA, Munich, Germany, 2016.

[27] X. Wu, L. Tan, J. Guo, Y. Wang, H. Liu, and W. Zhu, "A study of allocative efficiency of $\mathrm{PM}_{2.5}$ emission rights based on a zero sum gains data envelopment model," Journal of Cleaner Production, vol. 113, pp. 1024-1031, 2016.

[28] J. Guo, D. Zhu, X. Wu, and Y. Yan, "Study on environment performance evaluation and regional differences of strictlyenvironmental-monitored cities in China," Sustainability, vol. 9, no. 12, pp. 2094-2114, 2017.

[29] S. Zhang, D. Li, S. Li, H. Jiang, and Y. Shen, "Analysis of regional total factor energy efficiency in China under environmental constraints: based on undesirable-minds and DEA window model," IOP Conference Series: Earth and Environmental Science, vol. 69, pp. 1204-1220, 2017.

[30] Y. Li, Y. Chiu, and L. Lu, "Urban energy environment efficiency in China: based on dynamic meta-frontier SBM," Journal of the Air \& Waste Management Association, vol. 69, pp. 1-13, 2018.

[31] Environmental Protection Administration, https://taqm.epa. gov.tw.

[32] M. J. Farrell, "The measurement of productive efficiency," Journal of the Royal Statistical Society. Series A (General), vol. 120, no. 3, pp. 253-281, 1957.

[33] A. Charnes, W. W. Cooper, and E. Rhodes, "Measuring the efficiency of decision making units," European Journal of Operational Research, vol. 2, no. 6, pp. 429-444, 1978.

[34] R. D. Banker, A. Charnes, and W. W. Cooper, "Some models for estimating technical and scale inefficiencies in data envelopment analysis," Management Science, vol. 30, no. 9, pp. 1078-1092, 1984.

[35] K. Tone, "A slacks-based measure of efficiency in data envelopment analysis," European Journal of Operational Research, vol. 130, no. 3, pp. 498-509, 2001.

[36] R. Färe, S. Grosskopf, M. Norris, and Z. Zhang, "Productivity growth, technical progress, and efficiency change in industrialized countries," The American Economic Review, vol. 84, pp. 66-83, 1994.

[37] R. Färe and S. Grosskopf, "Productivity and intermediate products: a frontier approach," Economics Letters, vol. 50, no. 1 , pp. 65-70, 1996.

[38] C.-M. Chen, "A network-DEA model with new efficiency measures to incorporate the dynamic effect in production networks," European Journal of Operational Research, vol. 194, no. 3, pp. 687-699, 2009.

[39] K. S. Park and K. Park, "Measurement of multiperiod aggregative efficiency," European Journal of Operational Research, vol. 193, no. 2, pp. 567-580, 2009.

[40] K. Tone and M. Tsutsui, "Dynamic DEA: a slacks-based measure approach," Omega, vol. 38, no. 3-4, pp. 145-156, 2010. 